\title{
Research Notes
}

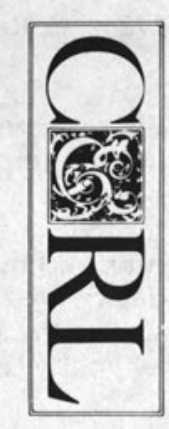

\section{Determination of Sample Size and Selection of the Sample: Concepts, General Sources, and Software}

\section{Peter Hernon}

This article provides an introduction to sampling, determination of sample size, and selection of the actual sample. Given the complexity of the topic and the impossibility of covering all aspects of sampling in a brief article, the author focuses on concepts, general sources, and sampling software. These concepts are central to the computation of sample size for a random sample. The article identifies sources that provide formulae and procedures for determining sample size. By reading the literature referenced and exploring different software products, librarians conducting research and evaluation studies will better understand probability sampling and the decisions underlying the use of a particular sample size.

hree questions that librarians planning a quantitative-based research project and graduate students taking a research methods course or completing a master's thesis/paper ordissertation often ask are:

- How big a sample do I need?

- How do I calculate the sample size?

- How do I draw that sample - select the actual subjects from the population?

The answer to the first question is complex and depends on a variety of factors, including the type of sampling method used, sampling error, the confidence level, precision, standard deviation, and the way in which the data will be analyzed. The answer to this question im- pacts how the second question is approached and answered. Addressing the second question may directly involve the negotiation of a mathematical formula, one that, at first glance, may appear incomprehensible. The third question often focuses on procedures and methods for selecting the actual subjects.

The purpose of this article is threefold: (1) to provide a brief introduction to concepts central to the computation of sample size; (2) to identify some basic articles and books that discuss these concepts, that provide readers with easily understandable presentations and with examples, and that many academic libraries are likely to have; and (3) to iden-

Peter Hernon is a Professor in the Graduate School of Library and Information Science at Simmons College, Boston, Massachusetts 02115. 
tify microcomputer software that determines sample size. For illustrative purposes, the concepts are applied to one formula commonly found in the literature, and the appropriate sample size is determined. There is also a brief discussion of the selection of a sample size for a hypothetical problem.

\section{SAMPLING}

As the U.S. General Accounting Office (GAO) observes,

Sampling is nothing new or unusual. For thousands of years, people have been basing judgments about a large group of objects on their observations of a few of them. Prehistoric humans probably decided whether the berries on a bush were edible by tasting a few of them (with possibly fatal results). At harvest time, farmers judged the quality and expected yield of a wheat field by rubbing the husks off a few ears of grain pulled from various parts of the field. People have used sampling techniques such as spot checking for many years. The great improvement in the last hundred years or so has been the development of statistical sampling. We now have ways of drawing and analyzing samples to produce more objective information of better quality and of being explicit about its limitations. ${ }^{1}$

Social science research, including that in library and information science, commonly uses statistical sampling, especially when resource constraints make it inefficient (in terms of cost, time, and effort) to examine a population. By engaging in statistical sampling, researchers determine "the sample size necessary to provide sample results having a certain measure of the risk of being wrong required for the population being examined and the evaluation question being examined [or the hypothesis being tested]."2

\section{SAMPLING METHOD}

Sampling method refers to the type of sampling procedure used. The purpose of probability sampling is to make a statistical inference or to select a sample, or portion of a universe, that is representative of that universe or population.
Probability sampling includes, for instance, simple random sampling and stratified random sampling, as well as systematic sampling and cluster sampling. Nonprobability sampling does not support generalization; rather the focus is on the sample itself. Nonprobability sampling, on the other hand, is discretionary and covers quota sampling, purposive or judgmental sampling, convenience sampling, and other methods. Ronald R. Powell provides an excellent introduction to both probability and nonprobability sampling, and the GAO offers detailed coverage of probability sampling. ${ }^{3}$

The GAO, in another important publication, discusses the selection of case study sites for anyone engaged in either qualitative or quantitative research. ${ }^{4}$ Site or instance selection may be based on convenience, purpose (requires knowledge of the characteristics of the population), or probability. As shown in table 1, each addresses a specific question. "Only rarely will convenience be a sound basis for instance selection; only rarely will probability sampling be feasible. Thus, instance selection on the basis of the purpose of the study is the most appropriate method in many designs." ${ }^{5}$

This article focuses on probability sampling, primarily the use of simple random sampling, which involves the selection of cases or subjects so that each one has an equal and known chance of inclusion and the selection of one case or subject does not influence the selection of another. Before basing the study procedure on random sampling, however, it is useful to consider other methods of sample selection. ${ }^{6}$ After all, there are times when nonprobability sampling, as well as other methods of probability sampling, might be needed and appropriate.

\section{SAMPLING ERROR}

According to Hubert M. Blalock, Jr., researchers who are planning or are in the process of conducting a study, or who are analyzing and interpreting data, must consider total error, which consists of two independent types of error: sampling and nonsampling error. ${ }^{7}$ 
TABLE 1

INSTANCE SELECTION IN CASE STUDIES *

\begin{tabular}{ll}
\hline $\begin{array}{l}\text { Selection Basis } \\
\text { Convenience }\end{array}$ & $\begin{array}{c}\text { When to Use and What Questions It Can Answer } \\
\text { purposes? What is happening here and why? }\end{array}$ \\
$\begin{array}{l}\text { Purpose } \\
\text { Bracketing }\end{array}$ & What is happening at the extremes? What explains such differences? \\
$\begin{array}{l}\text { Best cases } \\
\text { Worst cases }\end{array}$ & What accounts for an effective program? \\
$\begin{array}{ll}\text { Cluster } & \text { Why is the program not working? } \\
\text { Representative } & \text { How do different types of programs compare with each other? } \\
\text { In instances chosen to represent important variations, what is the } \\
\text { program like and why? }\end{array}$ \\
$\begin{array}{ll}\text { Special interest } & \text { In a typical site, what is happening and why? } \\
\text { Probability } & \text { What is happening in the program as a whole and why? }\end{array}$
\end{tabular}

- Source: U.S. General Accounting Office, Case Study Evaluations (Washington, D.C., 1990), 23.

Sampling error is the extent to which the means of repeatedly drawn samples deviate from each other and presumably the population mean. "The general rule of thumb for the size of the sample is... the larger the better"; the larger the sample the smaller is the sampling error. ${ }^{8}$ By examining the population, researchers seek to minimize sampling error; there still may be a problem, for instance, due to a faulty listing or identification of the population.' However, they still risk nonsampling error; errors, for instance, in data processing; errors in the responses, the observations made, and the instrument itself; and errors due to nonresponse or misrepresentation (e.g., falsified or misleading records). ${ }^{10}$

"There is no point in utilizing a sample that is larger than necessary; doing so unnecessarily increases the time and money needed for a study." At the same time, "samples that are quite small place significant limitations on the types of statistical analyses that can be employed."12 Researchers trying to minimize sampling error for impact assessments, which examine whether or not interventions have their intended effects, will profit from reading Evaluation: $A$ Systematic Approach, which discusses such assessments in the context of the "net effects" of an intervention, or "an estimate of the im- pact of the intervention uncontaminated by the influence of other processes and events that also may affect the behavior or conditions at which the social program being evaluated is directed."13

Some research methods textbooks refer to precision, which is the amount of sampling error that can be tolerated but that will still permit the results to be useful, as tolerance, tolerable error, or the bound on error. To calculate precision, it is necessary to compute the standard deviation, which is a numerical measure of the dispersion of scores around the mean; standard deviation is the square root of variance, which is also an indicator of dispersion.

\section{The purpose of probability sampling is to make a statistical inference or to select a sample, or portion of a universe, that is representative of that universe or population.}

Because it is not always possible to know the standard deviation, formulae for determining sample sizes that require the calculation and inclusion of that statistic may not always be practical to use. Fortunately, Gary T. Henry offers various suggestions for estimating 
variance and the standard deviation. He then illustrates how to determine sample size using a formula involving standard deviation. ${ }^{14}$ Therefore, anyone needing to include the standard deviation should review Henry's thoughtful suggestions.

\section{CONFIDENCE LEVEL}

In library and information science, the confidence level, or an acceptable level of probability, is usually set at 95 percent (the .05 level), which means that there is a 95 percent chance that the sample is distributed in the same way as the population. The confidence level might be set at 99 percent (the .01 level) or 90 percent (the .10 level). The 90 percent level requires the smallest sample but increases the chance of making a profound sampling error.

\section{DETERMINATION OF SAMPLE SIZE}

A number of sources provide a formula for calculating appropriate sample sizes. For example, Powell reproduces a formula requiring knowledge of the population's standard deviation. ${ }^{15}$ Bruce W. Tuckman reports a very useful formula, one addressing "a single dichotomous stratification parameter" (e.g., "private-public, urban-rural, largesmall) and with random sampling within each category." ${ }^{16}$ His formula introduces $z$ or the standard score that corresponds to a given confidence level; "for a 90 percent confidence level, $z=1.65$; for a 95 percent confidence level, $z=1.96$; for a 99 percent confidence level, $z=2.58 .^{\prime \prime} 17$ Peter Hernon and Charles R. McClure modify Tuckman's formula and example. ${ }^{18}$ Examples of other formulae include one by Hubert M. Blalock, Jr., Robert Swisher and Charles R. McClure, Charles H. Busha and Stephen P. Harter, Margaret Slater, and I. S. Simpson. ${ }^{19}$

M. Carl Drott presents a table for determining sample size and discusses three examples for the selection of a sample: (1) one for examining library records, (2) one for studying the perceptions of library patrons about library services, and ( 3 ) one for investigating the condition of books in the collection. ${ }^{20}$ Cheryl Metoyer-Duran, in an appendix, guides readers conducting readability studies in the selection of paragraphs from published and unpublished works. ${ }^{21}$

Powell, Hernon, Slonim, Isaac and Michael, and Cohen, among others, reprint tables of sample sizes for a given population. ${ }^{22}$ However, such tables "may represent a rather simplistic, and quite possibly conservative, method for ascertaining a sample size."23

Some microcomputer software packages permit the determination of sample size (see, e.g., appendix A). Before using such a package, however, review its scope, authority, accuracy, audience, uses, easy of learning and use, documentation, and hardware and installation specification. ${ }^{24}$ Appendix IV of the GAO's Using Statistical Sampling identifies some other computer software packages that perform sampling computations. ${ }^{25}$ StatPac Gold, a statistical analysis package that is not covered in either the appendix of this paper or the appendix of the GAO manual, has an easyto-follow routine in its "utility" program for determining a sample size. ${ }^{26} \mathrm{Dr}$. Drott's Random Sampler, a newly released software package, guides its users in the selection of a sample size based on a simple random sample. There is also an opportunity to adjust the sample size to accommodate the size of a known population, and a handy feature enables researchers to determine the size of a sample for more than one numeric or nonnumeric stratum or category, e.g., a month, days of the week, or hours of the day. ${ }^{27}$

\section{DRAWING A SAMPLE}

To assist those attempting to answer the third question posed at the beginning of the article- "How do I draw that sample?" once I know the sample sizePowell reprints a table of random numbers from A Million Random Digits with 100,000 Normal Deviates and illustrates the application of the table to selection of the actual sample. ${ }^{28}$ Appendix II of GAO's manual to guide agency evaluators provides a much more detailed discussion of using a random number table and selecting the sample. ${ }^{29}$ Using StatPac Gold, it is possible to: (1) generate a random number table that randomly selects 
Formula:

$$
N=\frac{Z^{2}}{E}(P)(1-P)
$$

$N=$ sample size

$Z=$ desired confidence level (see note 15)

$E=$ acceptable degree of sampling error

$P=$ estimated proportion or incidence of cases in the population (range is from .01 to .99)

Example:

Private colleges account for $50 \%$ of the baccalaureate colleges in the geographical region.

* Proportion of cases of private baccalaureate colleges in the population is $.25(P=.50)$

* Desired confidence level is $95 \%(z=1.96)$

* Acceptable degree of error is .10 ( = plus or minus $10 \%$ )

$$
N=\frac{(1.96)^{2}}{.10}=(.50)(.50)=10
$$

\section{FIGURE 1}

Application of One Formula

numbers until the sample size is achieved, and (2) select a specified number of random records from a data file and write them to a new file. Dr. Drott's Random Sampler also assists in the selection of specific subjects from the population and in sorting random numbers in ascending or descending order.

\section{SUMMARY}

Figure 1, which identifies one formula for calculating sample size, shows the application of different concepts discussed in this article. To produce a .10 sampling error and a 95 percent confidence level, the sample requires ten private baccalaureate institutions. If researchers use either StatPac Gold or Dr. Drott's Random Sampler, they would set the precision, confidence, and variability. It is possible to adjust the sample size to reflect population size. Statistical Sample Planner is an example of a more complex, but inexpensive, package. It affords greater opportunity to adjust sample size according to other factors, e.g., the cost of the study.

Returning to the ten institutions, researchers might also use statistical sam- pling again. Depending on the research problem and the target population within those institutions (e.g., all or certain library staff, faculty, or students), they might select a random sample of that population. As an alternative, they might stratify the population (e.g., students according to class level or faculty according to the social sciences, humanities, and sciences) and then draw a random sample. Dr. Drott's Random Sampler and Statistical Sample Planner are examples of software useful in drawing a stratified random sample.

\section{Some microcomputer software packages permit the determination of sample size.}

Taking a hypothetical example, let us suppose that the staff of a college library wants to survey the student body about its use and nonuse of library services and resources. They would find that a sample size of 384 has 95 percent confidence, plus or minus 5. Using StatPac Gold, as one example, they could adjust 
the sample size to accommodate the actual size of the student body. Presuming that there were 3,000 students, the adjusted sample size is 340 .

Now, let's assume that the staff want to examine student use of the Internet or remote use of the online catalog. For that study, they might lack specific information about which students do and do not use either the Internet or the online catalog. In such instances, they might adopt a nonprobability sample and engage in focus group interviewing of actual users and nonusers. ${ }^{30}$

As this section indicates, researchers have choices. An examination of the literature referenced in this article as well as published studies will enable them to identify the choices and make appropriate decisions.

\section{CONCLUSION}

In designing a research study, it is important to decide whether to study the population or a sample. If the decision is to examine a sample representative of the population, the appropriate type of sampling method and sample size must be identified and used; in such an instance, the researcher expects to generalize from the sample to the population. At the same time, sound decisions regarding the reflective inquiry (problem statement, literature review, theoretical framework, logical structure, and, if appropriate, objectives, research questions, and hypotheses), methodology, and data analysis and interpretation must be made. ${ }^{31}$ David $\mathrm{R}$. Krathwohl reminds researchers that a weak link at any one of these stages may weaken or invalidate study findings, recommendations, and conclusions. ${ }^{32}$ Fortunately, "the body of literature on LIS research methods is growing and has more advice than ever to offer readers planning to conduct research, or read research findings, about library and information related problems."

\section{REFERENCES AND NOTES}

1. U.S. General Accounting Office. Program Evaluation and Methodology Division, Using Statistical Sampling, GAO/PEMD-10.1.6 (Washington, D.C., 1992), 10-11. The series of transfer papers are free of charge upon request from the agency.

2. Ibid., 38-39. By examining research methods textbooks, as well as the research literature, novice researchers can identify instances in which sampling was used. Nonetheless, it would be helpful to have a database of the research literature in library and information science that identifies, for instance, the sampling method, statistical tests, confidence levels, and methodologies used. Such a datebase might make it easier for these researchers to obtain the necessary guidance in setting up and implementing a study.

3. Ronald R. Powell, Basic Research Methods for Librarians, 2d ed. (Norwood, N.J.: Ablex, 1991), 61-81; U.S. General Accounting Office, Using Statistical Sampling. See also Delbert C. Miller, Handbook of Research Design and Social Measurement, 5 th ed. (Newbury Park, Calif.: Sage, 1991), 60-64; Graham Kalton, Introduction to Survey Sampling, Sage University Paper 35 (Newbury Park, Calif.: Sage, 1983); Morris James Slonim, Sampling (New York: Simon \& Schuster, 1966); Mary Ann Moore, "The Place of Significance Testing in Contemporary Social Science" (Apr. 1991) (ERIC ED 333036); Ronald S. Palomares, "Alternatives to Statistical Significance Testing" (Nov. 1990) (ERIC ED 325524), I. S. Simpson, Basic Statistics for Librarians, 3d ed. (London: Library Association Publishing, 1988), chap. 4: Earl R. Babbie, Survey Research Methods (Belmont, Calif.: Wadsworth, 1990); Earl R. Babbie, The Practice of Social Research (Belmont, Calif.: Wadsworth, 1992); Seymour Sudman, Applied Sampling (San Diego, Calif.: Academic, 1976); Bill Williams, A Sampler on Sampling (New York: Wiley, 1978).

4. U.S. General Accounting Office. Program Evaluation and Methodology Division, Case Study Evaluations, Transfer Paper 10.1.9 (Washington, D.C., 1990).

5. Ibid., 22.

6. See, for instance, Philip M. Clark, "Sample Size Determination: A Comparison of Attribute, Continuous Variable, and Cell Size Methods," Library \& Information Science Research 6 (1984): 407-23; U.S. General Accounting Office, Using Statistical Sampling 
62-67 (attribute sampling), 44-46 (stratified sampling), and 46 (cluster sampling). The GAO manual also discusses estimation, discovery sampling, and acceptance sampling. Also of value is Jack E. Kiger and Kenneth Wise, "Attribute Sampling: A Library Management Tool," College \& Research Libraries 54 (Nov. 1993): 537-49.

7. Hubert M. Blalock, Jr., Social Statistics, 2d ed. (New York: McGraw-Hill, 1972), 529-30.

8. Powell, Basic Research Methods for Librarians, 73. See also John T. Roscoe, Fundamental Research Statistics for the Behavioral Sciences (New York: Holt, 1969), 156-57.

9. Abraham Bookstein, "How to Sample Badly," Library Quarterly 44 (Apr. 1974): 124-32.

10. For a discussion of sampling and nonsampling error, see Peter Hernon, Statistics: $A$ Component of the Research Process, rev. ed. (Norwood, N.J.: Ablex, 1994), chap. 4, Robert M. Groves, Survey Errors and Survey Costs (New York: Wiley, 1989).See also Robert M. Groves, Robert B. Cialdini, and Mick P. Couper, "Understanding the Decision to Participate in a Survey," Public Opinion Quarterly 56 (Winter 1992): 475-95.

11. Powell, Basic Research Methods for Librarians, 73. See also John H. Mueller, Karl F. Schuessler, and Herbert L. Costner, Statistical Reasoning in Sociology, 3d ed. (Boston: Houghton, 1977), 407.

12. Powell, Basic Research Methods for Librarians, 74.

13. Peter H. Rossi and Howard E. Freeman, Evaluation: A Systematic Approach, 5th ed. (Newbury Park, Calif.: Sage, 1993), 215.

14. Gary T. Henry, Practical Sampling (Newbury Park, Calif.: Sage, 1990), 119-20. He also discusses the use of weights "when the sample has not been selected with equal probability. Unequal probability of selection can produce sampling bias" (129).

15. Powell, Basic Research Methods for Librarians, 74. See also Ray L. Carpenter and Ellen S. Vasu, Statistical Methods for Librarians (Chicago: ALA, 1978), 39.

16. Bruce W. Tuckman, Conducting Educational Research, 2d ed. (New York: Harcourt, 1978), 205-6, 231-32.

17. Ibid., 232 .

18. Peter Hernon and Charles R. McClure, Evaluation and Library Decision Making (Norwood, N.J.: Ablex, 1990), 113-15.

19. Hubert M. Blalock, Jr., Social Statistics, rev. 2d ed. (New York: McGraw-Hill, 1979), 215-18; Robert Swisher and Charles R. McClure, Research for Decision Making (Chicago: ALA, 1984), 103-28; Charles H. Busha and Stephen P. Harter, Research Methods in Librarianship: Techniques and Interpretation (San Diego, Calif.: Academic, 1980), 258-61\% Margaret Slater, Research Methods in Library and Information Studies (London: Library Association, 1990), 36-37; I. S. Simpson, Basic Statistics for Librarians, 43-48.

20. M. Carl Drott, "Random/Sampling: A Tool for Library Research," College \& Research Libraries 30 (Mar. 1969): 119-25.

21. Cheryl Metoyer-Duran, "The Readability of Published, Accepted, and Rejected Papers Appearing in College \& Research Libraries," College \& Research Libraries 54 (Nov. 1993): 517-26.

22. Powell, Basic Research Methods for Librarians, 73; Hernon, Statistics; Slonim, Sampling; Stephen Isaac and William B. Michael, Handbook in Research and Evaluation (San Diego, Calif.: EdITS, 1981), 193; Jacob Cohen, Statistical Power Analysis for the Behavioral Sciences (San Diego, Calif.: Academic, 1977).

23. Powell, Basic Research Methods for Librarians, 75.

24. For a complete list of "evaluative criteria for general purpose statistical packages," see Peter Hernon and John V. Richardson, Microcomputer Software for Performing Statistical Analysis: A Handbook Supporting Library Decision Making (Norwood, N.J.: Ablex, 1988). Because it is easy and convenient to determine the sample size using some software, novice researchers should first read the sources referenced in this article so as to ensure a proper understanding of the concepts involved and to review the full range of sampling methods that might be used. For some projects, they should seek assistance from a statistician, other researchers, or a technical assistance group.

25. U.S. General Accounting Office, Using Statistical Sampling, 214-20. As the GAO correctly warns, "all statistical software packages can easily be misapplied and their results easily misinterpreted. Sometimes, this is the result of the user's failure to completely understand the assumptions the package makes in performing the analysis" (215). 
26. StatPac Gold IV is available from Walonick Associates, 3814 Lyndale Ave. South, Minneapolis, MN 55409. See Hernon, Statistics, chap. 3.

27. M. Carl Drott, Dr. Drott's Random Sampler: Using the Computer as a Tool for Library Management (Englewood, Colo.: Libraries Unlimited, 1993). This software is available for either an IBM PC, or compatible, or Macintosh microcomputer. The accompanying 77-page manual highlights concepts and use of the software. It also offers examples.

28. Powell, Basic Research Methods for Librarians, 67; Rand Corporation, A Million Random Digits with 100,000 Normal Deviates (New York: Free Pr., 1955).

29. U.S. General Accounting Office, Using Statistical Sampling, app. II, 144-79.

30. See David W. Stewart and Prem N. Shamdasani, Focus Groups: Theory and Practice (Newbury Park, Calif.: Sage, 1990).

31. See, for example, Hernon, Statistics, chap. 1; Hernon and McClure, Evaluation and Library Decision Making, chaps. 4-5; Miller, Handbook of Research Design and Social Measurement. See also Ronald R. Powell, "Guides to Conducting Research in Library and Information Science," in Library and Information Science Research: Perspectives and Strategies for Improvement, ed. Charles R. McClure and Peter Hernon (Norwood, N.J.: Ablex, 1991), 15-30. Powell identifies more than 90 guides.

32. David R. Krathwohl, Social and Behavioral Science Research (San Francisco: Jossey-Bass, 1985).

33. Powell, "Guides to Conducting Research in Library and Information Science," 25.

\section{APPENDIX A \\ EXAMPLES OF MICROCOMPUTER SOFTWARE}

BUSINESS STATISTICS (Lionheart Press, P.O. Box 20756, Mesa, AZ 85277-0756). Compatible Hardware: Apple Macintosh, Amiga-DOS, MS-DOS.

Memory Required: $512 \mathrm{k}$.

Description: Stratified sampling, cluster sampling, sequential sampling, binomial and hypergeometric sampling schemes. Also provides statistical procedures.

CUSTOM QC (Stochos, Inc., 14 N. College St., Schenectady, NY 12305; 518-372-5426). Compatible Hardware: IBM PC, PC XT, PC AT, PS /2 \& compatibles. Operating System(s): PC-DOS, MS-DOS, UNIX.

Memory Required: 640k.

Description: Provides statistical procedures as well as variable and attribute plan determination (sampling plan).

EXPERIMENTAL STATISTICS (Lionheart Press, P.O. Box 20756, Mesa, AZ 85277-0756). Compatible Hardware: Apple Macintosh, Amiga-DOS, MS-DOS.

Memory Required: 512k.

Description: Stratified sampling, cluster sampling, sequential sampling, binomial and hypergeometric sampling schemes. Also provides statistical procedures.

EX-SAMPLE (The Idea Works, Inc., 607 Jackson St., Columbia, MO 65203; 314-875-5827). Compatible Hardware: Any MS-DOS compatible machine. Operating System(s): MS-DOS.

Memory Required: $512 \mathrm{k}$.

Description: Power analysis and traditional methods for estimating minimal sample size for surveys and other types of studies. Offers a detailed written justification of sample size recommendations and adjusts achieved sample size for multiple groups, response rates, and contamination. Has on-screen tutorial.

QCPAC STATISTICAL QUALITY CONTROL ON THE IBM PC (Marcel Dekker, 270 Madison Ave., New York, NY 10016; 212-696-9000).

Compatible Hardware: IBM PC.

Memory Required: 64k.

Description: This package accompanies Steve Zimmerman's book, Statistical Quality Control (New York: Dekker, 1985). 
STATGRAPHICS (Statistical Graphics Corp., 5 Independence Way, Princeton, NJ 08540; 609-9249374).

Compatible Hardware: IBM PC and compatibles

Operating System(s): DOS 2.0 or higher

Memory Required: 640k

Description: Determines sample size, has random number generation of 40,000 data points, and provides graphical and statistical procedures.

STATISTICAL SAMPLE PLANNER (Dynacomp, The Dynacomp Office Bldg., 178 Phillips Rd., Webster, NY 14580; 716-265-4040).

Compatible Hardware: Apple II with Applesoft, IBM PC.

Operating System(s): Apple, DOS 3.2 or 3.3, MS-DOS.

Memory Required: Apple 48k, IBM 128k.

Description: Covers a stratified random sampling plan. The software enables researchers to address factors such as cost of the study. A 28-page manual includes theory, formulae, and examples.

TRUE EPISTAT 4.0 (EPISTAT Services, 2011 Cap Rock Circle, Richardson, TX 75080-3417; 214-6801376).

Compatible Hardware: IBM PC, XT, AT and System II microcomputers and most compatibles.

Requires hard disk and a Hercules monochrome or any color CGA, EGA, or VGA.

Operating System(s): MS-DOS 3.1 or later.

Memory Required: 512k.

Description: Draws power curves and can provide random numbers and random allocations of cases and controls. Calculates sample sizes for six common kinds of studies, including surveys, paired case-control studies, and unpaired case-control studies. Also provides statistical procedures.

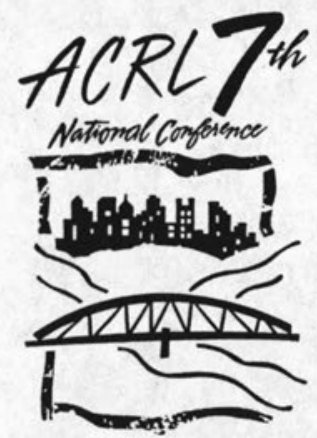

CALL FOR

PAPERS and PROPOSALS
Association of College and Research Libraries March 29-April 1,1995, Pittsburgh, Pennsylvania THEME: Continuity and Transformation: The Promise of Confluence

Theme tracks: 1) Knowledge workers and their organizations, 2) Technology and the service-centered library, 3) Multiculturalism and internationalism, and 4) Society, economics, and politics.

You are invited to submit proposals for panel discussions, contributed papers, debate sessions, poster sessions, and other presentations. Letters of intent to present are due to the Program Committee by May 1, 1994. Review of proposals begin on July 15,1994.

For guidelines send E-mail to U22733 @ uicvm.uic.edu, or fax to $312 / 280-2520$, or phone Althea Jenkins, 312/280-3248. 


\section{TECHNOLOGY FOR THE 90's AND FOR THE LIBRARIES OF TOMORROW}

\section{BLACKWELL'S PROUDLY INTRODUCES...}

\section{FOR COLLECTION DEVELOPMENT}

$$
\text { BLACKWELL'S } \frac{\text { TOCONLINE }}{\text { TOCO }}
$$

$\mathrm{B}$ lackwell's New Titles Online database now includes Tables of Contents and Descriptive Summaries for new and forth-coming scholarly monographs.

- Browse the contents pages before placing the order

- View the publisher's title description

- Order the title electronically

- Insure a title is included on approval

- Access through the INTERNET

\section{FOR PUBLIC ACCESS CATALOGS BLACKWELL'S 505}

Blackwell's MARC With Books ${ }^{\circledast}$ service now offers LCMARC records enriched with Tables of Contents.

- Enhance subject access

- Improved chapter-level author access

- View contents \& summaries in your PAC before searching the shelves

- Increase interlibrary loan efficiency

FIND OUT HOW EASY AND COST EFFECTIVE IT CAN BE TO GET CONTENTS INFORMATION TO BOTH YOUR STAFF AND PATRONS TODAY!

\section{BLACKWELL NORTH AMERICA, INC. TECHNICAL SERVICES DIVISION}

